\title{
Extended SWAT model for dissolved reactive phosphorus transport in tile-drained fields and catchments
}

Shenglan Lu*

Department of Bioscience, Aarhus University, Vejlsøvej 25, P.O. Box 314, 8600 Silkeborg,

Denmark. Tel: +45 871 58407. Email: sl@bios.au.dk

Hans Estrup Andersen

Department of Bioscience, Aarhus University, Vejlsøvej 25, P.O. Box 314, 8600 Silkeborg,

Denmark. Email: hea@bios.au.dk

Hans Thodsen

Department of Bioscience, Aarhus University, Vejlsøvej 25, P.O. Box 314, 8600 Silkeborg,

Denmark. Email: hath@bios.au.dk

Gitte Holton Rubæk

Department of Agroecology, Aarhus University, Research Centre Foulum, P.O. Box 50, 8830 Tjele,

Denmark.

Email: gitte.rubaek@agro.au.dk

Dennis Trolle

Department of Bioscience, Aarhus University, Vejlsøvej 25, P.O. Box 314, 8600 Silkeborg,

Denmark. Email: trolle@bios.au.dk

*(Corresponding author)

Page 1 of 29

(C) 2015. This manuscript version is made available under the Elsevier user license http://www.elsevier.com/open-access/userlicense/1.0/ 


\begin{abstract}
We developed extensions (DrainP) for the Soil and Water Assessment Tool version 2012 (SWAT2012) to simulate leaching of dissolved reactive phosphorus (DRP) throughout soils with the Langmuir isotherm, and the subsequent transport from tile drains to streams. The DrainP module was evaluated for two small tile-drained fields and the River Odense catchment (486 km²) in Denmark. DrainP not only simulated well monthly DRP yields in the tile-drained fields but also improved the overall catchment DRP yields, and provided new insights into the source allocation of DRP at the catchment scale. The simulated soil total phosphorus (TP) accumulation in the tillage layer fell within the range of measurements.
\end{abstract}

Keywords:

Tile drain, DRP, soil TP accumulation, lowland, SWAT, leaching, Langmuir isotherm. 


\section{Extended SWAT model for dissolved reactive phosphorus transport in tile-drained fields and catchments}

\section{Introduction}

Phosphorus (P) is often an important factor for eutrophication and a key concern regarding the ecological status in freshwater systems (Sharpley et al., 1994; Carpenter et al., 1998). P input to aquatic systems consists of mixed soluble and particulate forms and turnover among different P pools is dynamic (Correll, 1998). Among all forms of P, dissolved reactive P (DRP) is readily utilised by bacteria, algae and plants (Correll, 1998). Moreover, DRP can be the dominant P form in watercourses within agricultural catchments and grasslands (Haygarth et al., 1998; Heathwaite and Dils, 2000; Kronvang et al., 2007). Therefore, it is important to understand and be able to quantify the transport and track the sources of DRP in those areas. In lowland agricultural catchments, tile drains have been widely installed to drain excessive water (Smedema et al., 2000; Blann et al., 2009). In some areas, tile drains have been estimated to contribute $30 \%$ to $60 \%$ of the stream flow (Xue et al., 1998; Kiesel et al., 2010; Koch et al., 2013). Moreover, intensive fertilization over decades can lead to accumulation of $\mathrm{P}$ in soils, which increases the risk of $\mathrm{P}$ leaching (Ekholm et al., 2005; Rubæk et al., 2013). As a result, tile drains rather than surface runoff can be a dominant source (>40\%) for the DRP loads to surface waters in P accumulated areas (Schmalz et al., 2007; King et al., 2014a). Even though DRP concentrations during low tile drain flow are often less than those observed during surface runoff events (Haygarth et al., 1998; Simard et al., 2000), many studies have reported that DRP concentrations during high tile drain flow exceed limits for eutrophication (Dils and Heathwaite, 1999; Blann et al., 2009; King et al., 2014b). Besides DRP, tile drains also transport fine sediments and other forms of $\mathrm{P}$ to the receiving waters (Kronvang et al.,1997; Russel et al., 2001). 
Modelling tools have been widely used to assess DRP losses from agricultural areas. Kleinman et al. (2015) and Radcliffe et al. (2015) reviewed modelling tools for P losses from tile-drained areas and concluded that models simulating P in tile drains, such as the Agricultural Policy/Extension eXtender (APEX) model (Steglich and Willianms, 2013), HYDRUS (Šimůnek et al., 2008) and the Phosphorus LEAching from Soils to the Environment (PLEASE) model (Schoumans et al., 2013), are designed and therefore only suitable for the plot or field scale, whereas catchment models lack certain components to predict DRP losses from tile drains: The Hydrologic Simulation Program-Fortran (HSPF) model (Bicknell et al., 1997) does not simulate tile drain flow directly and the ICECREAMDB model (Larsson et al., 2007) tends to underestimate DRP in P-saturated soils (Radcliffe et al., 2015). The worldwide applied catchment model Soil and Water Assessment Tool (SWAT) (Arnold et al., 1998) does not calculate DRP loss from tile drains but contains the key processes: surface and subsurface hydrology, phosphorus cycling and agricultural practices. Moriasi et al. (2013) implemented a Hooghoudt-Kirkman equation for tile drain flow simulation and a new method for shallow water table calculation in the soil (Moriasi et al., 2011) in the SWAT model version 2012 (SWAT2012). The new equations simulated well monthly tile drain flow and nitrate transport in a monitored tile-drained field, though the Hooghoudt-Kirkman equation and tile drain nutrient transport have not been validated at the catchment scale. Previous studies have shown that the SWAT model underestimates the DRP loads in tile-drained lowland catchments, where DRP is the dominant form of P in surface waters (Lam et al., 2011; Lam et al., 2012). A SWAT model for the River Odense catchment in Denmark also underestimated DRP yields, probably due to the lack of DRP transport from tile drains, which contributed 30\% of the stream flow (Lu et al., 2014). Therefore, the addition of DRP transport from tile drains in the SWAT model is necessary for simulation of P dynamics in lowland tile-drained catchments. 
SWAT2012 simulates DRP loss in surface runoff and allows DRP percolation from the top 10 mm soil to the underlying soil layer. However, DRP leaching to the deeper soil layers and transport to tile drains and from there to surface waters is not included. The DRP concentration ( $\left.\mathrm{mg} \mathrm{l}^{-1}\right)$ in the top $10 \mathrm{~mm}$ soil water in SWAT2012 is estimated from a linear sorption isotherm. Rossi et al. (2012) showed that the Langmuir isotherm simulates high DRP concentrations in surface runoff better than the linear isotherm in the SWAT model. Moreover, Nelson and Parsons (2006) found that the linear isotherm also underestimated P leaching in P-saturated soils, whereas the Langmuir isotherm improved the simulation of P percolation and $\mathrm{P}$ accumulation in the soil. Therefore, the Langmuir isotherm is more suitable for estimating DRP concentrations than the linear isotherm.

This study aims to achieve an extension of the SWAT model to enable simulations of DRP transport in tile-drained lowland catchments with more reliable source allocations. We developed an extension, named DrainP, to the SWAT2012 code (revision 637) to simulate DRP transport to tile drains and further to surface waters. DrainP calculates DRP concentrations and leaching through the soil profile with the Langmuir isotherm deduced by Nelson and Parsons (2006) and DRP transported with the tile drain flow to surface waters. Tile drain flow and DRP transport to tile drains were first evaluated at the field scale at two monitored tile-drained fields in a Danish lowland

catchment. Subsequently, the impact of DrainP was evaluated at the catchment scale at the $428 \mathrm{~km}^{2}$ River Odense catchment in Denmark.

\section{Material and methods}

\subsection{SWAT extension module for DRP transport to tile drains (DrainP)}

The SWAT model divides catchments into sub-basins according to a digital elevation model (DEM) and an optional user-input stream network. Then each sub-basin is further divided into hydrological response units (HRUs), which are unique combinations of land use, soil type and 
topography (slope) and consist the smallest building blocks of the semi-distributed model. In each HRU, water balance, sediment erosion, crop growth, nutrient and pesticide movements are calculated and then summed at sub-basin level and routed through the streams (Neitsch et al., 2011). The DRP leaching module is active in all HRUs, whereas the amount of DRP transported from tile drains is active only in the tile-drained HRU, summed up at sub-basin level and then routed to the streams.

\subsubsection{Leaching module}

Van der Zee and Bolt (1991) describe the equilibrium between DRP concentrations in soil water $(C)$ and inorganic $\mathrm{P}$ adsorbed to soil constituents $(N)$ with the Langmuir isotherm as:

$$
C=\frac{N}{k_{L}\left(N_{\max }-N\right)}
$$

where $C$ is the DRP concentration in soil water ( $\left.\mathrm{mg} \mathrm{l}^{-1}\right), N$ is inorganic $\mathrm{P}$ adsorbed to soil $\left(\mathrm{mg} \mathrm{kg}^{-1}\right)$, $k_{L}$ is the Langmuir adsorption constant $\left(\mathrm{l} \mathrm{mg}^{-1}\right)$ and $N_{\text {max }}$ is the adsorption maximum (mg kg-1 $)$. Vadas and White (2010) validated the soil P processes in the SWAT model and outlined that "solution P" in the SWAT model represents both the inorganic P in soil water and the P weakly adsorbed to the soil matrix. Therefore, "solution P" in the SWAT model will be referred to as labile $\mathrm{P}$ in this study, whereas dissolved inorganic $\mathrm{P}$ in soil water (which is part of the labile $\mathrm{P}$ ) will be referred to as DRP. Nelson and Parsons (2006) calculated DRP concentration in each soil layer $\left(C_{l y}\right)$ with labile P using the Langmuir isotherm and deducted equation (1) to:

$$
C_{l y}=\frac{-b+\sqrt{b^{2}-4 a c}}{2 a}
$$

$$
\begin{aligned}
& a=k_{L} \theta_{l y} \\
& b=N_{\text {max }, l y} k_{L} \rho_{b, l y}+\theta_{l y}-\frac{P_{l a b i l e, l y} N_{\text {max }, l y}}{z_{l y}} \\
& c=-\frac{P_{l a b i l e, l y}}{z_{l y}}
\end{aligned}
$$


$\theta_{l y}$ is the relative soil moisture content of the soil layer $\left(\mathrm{mm} \mathrm{mm}^{-1}\right), \rho_{b, l y}$ is the bulk density of the soil layer $\left(\mathrm{Mg} \mathrm{m}^{-3}\right), P_{\text {labile,ly }}$ is the labile $\mathrm{P}$ in the soil layer $\left(\mathrm{kg} \mathrm{P} \mathrm{ha}^{-1}\right)$ and $z_{l y}$ is the soil layer thickness (mm).

$N_{\text {max }}$ in variable $b$ Equation (2) can be estimated from the sum of oxalate extractable aluminium and iron concentrations (Van der Zee and Van Riemsdijk, 1988):

$$
N_{\max }=\beta_{m}\left(A l_{o x}+F e_{o x}\right) \cdot 31
$$

where $A l_{o x}$ and $F e_{o x}$ are oxalate extractable aluminium and iron concentrations in the soil (mmol $\left.\mathrm{kg}^{-1}\right), \beta_{m}$ is the maximum adsorption fraction and 31 is the atomic weight of $\mathrm{P}$. The amount of DRP leached to the next soil layer is calculated as the product of $C_{l y}$ and the water percolated to the next soil layer, and the mass of labile $\mathrm{P}$ is updated for each soil layer.

Equation (2) was implemented into the SWAT model code to calculate DRP concentration for the soil layer $\left(C_{l y}\right)$ with existing SWAT soil variables and phosphorus variable labile $\mathrm{P}$, the new variable $N_{\max }$ and a calibration parameter $k_{L}$. The new variable $N_{\max }$ is calculated based on user input of $A l_{o x}$ and $F e_{o x}$ and a calibration parameter $\beta_{m}$.

\subsubsection{Transport to the tile drain module}

Solutes transported with tile drain flow are often calculated with the solute concentration in each soil layer multiplied by the tile drain flow from each soil layer (Brevé et al., 1997; Larsson and Jarvis, 1999). However, tile drain flow is derived from the whole soil profile and not separately for each soil layer in the SWAT2012 model. Therefore, in the DrainP module, tile drain flow $\left(Q_{t i l e}\right)$ is partitioned among the soil layers situated between the perched shallow water table (swt) from the impermeable layer and tile drain depth (DDRAIN) (Figure 1). The contribution of each soil layer $\left(f r_{\text {tile,ly }}\right)$ to the tile drain flow is calculated from the layer thickness relative to the total height

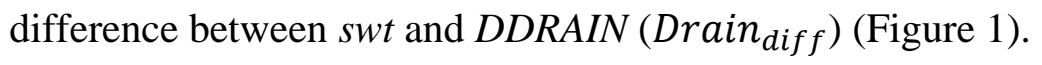


The amount of DRP transported via tile drain flow to the tile drains $\left(D R P_{\text {drain }}\right)$ is calculated as a sum of the tile drain flow in the SWAT model multiplied by the DRP concentration of each soil layer $C_{l y}$ from Equation (2) between swt and DDRAIN:

$$
D R P_{\text {drain }}=\sum_{l y=t o p}^{\text {bottom }} C_{l y} \cdot f r_{\text {tile }, l y} \cdot Q_{\text {tile }}
$$

\subsection{Study sites and monitoring}

The model was first tested on two monitored tile-drained fields located on the island of Funen, Denmark (Figure 2a), then on the River Odense catchment upstream of the Kratholm station (Kratholm) also on Funen (Figure 2a). The monitored tile-drained fields, TileL1 (4.5 ha) and TileL2 (2.8 ha), are located within the Lillebæk catchment $\left(4.28 \mathrm{~km}^{2}\right)$ at the southeast coast of Funen, while Kratholm is situated around $40 \mathrm{~km}$ northwest of the Lillebæk catchment.

In the Lillebæk catchment, the soil texture is mainly sandy loam (DK5067 in Table 2) with low to moderate permeability and poorly drained (Pedersen et al., 2010). Tile drains have been installed in $22 \%$ of the agricultural fields (Figure 2d) at depths between 0.8 and $1.4 \mathrm{~m}$ with a spacing of around $20 \mathrm{~m}$. Plastic tubes of $100 \mathrm{~mm}$ diameter were typically installed as drainage pipes in sandy loam soils. However, detailed information on tile drainage system was not available for the monitored tile-drained fields. Therefore drainage depth and spacing were subject to calibration (Table 3), whereas the effective radius of the drainage tubes (RE) was set to $50 \mathrm{~mm}$. TileL1 and TileL2 are both intensively cultivated and mainly fertilized with solid animal manure and slurry (Table 1). Agricultural management data on sowing and harvesting dates, fertilizer application and tillage operations were collected from previous farmer survey by Pedersen et al. (2010) (Appendix). Kratholm covers an area of $486 \mathrm{~km}^{2}$, dominated by agriculture (71\%) and sandy loam soils (DK5067 in Table 2). Tile drains are likely installed in around 40\% of the catchment area according to a national tile drain probability map (Olesen, 2009). Average annual precipitation on Funen was 
$840 \mathrm{~mm}$ during the study period from 1998 to 2006. During this period, August was the warmest month, with an average daily temperature of $17^{\circ} \mathrm{C}$, and January was the coldest month, with an average daily temperature of $-1^{\circ} \mathrm{C}$.

In TileL1 and TileL2, the water levels of the tile drain flow were measured continuously in a collecting well with a Thompson weir and a pressure sensor. Tile drain discharges were then calculated with the measured water levels and flow rating curves. Water for orthophosphate concentrations analysis was collected proportional to flow with automatic samplers in the collecting wells. Prior to analysis, water samples were pooled for discrete periods, typically for one week and ranging from one to nine days. The orthophosphate concentrations were measured with the Murphy and Riley (Murphy and Riley, 1962) method after filtering the composite water samples through 1.2 micrometre Whatman GF/C glass microfiber filters (Pedersen et al., 2010). Composite orthophosphate measurements in TileL1 and TileL2 were available from 1993, but the years 1995 to 1997 were very dry with very few measurements. Therefore, the study period chosen was 1998 onwards. The composite concentrations were linearly interpolated into daily concentrations to derive monthly DRP yields. At the Kratholm station, daily discharge and orthophosphate concentrations were available from 1998 onwards (Lu et al., 2014).

Soil P measurements were not available for the study sites; instead measurements of soil P were available on a $7 \mathrm{~km}$ grid covering Denmark with 337 grid points in agricultural and forest soils. Inventory data on total P (TP), oxalate extractable iron $\left(F e_{o x}\right)$ and aluminium $\left(A l_{o x}\right)$ at $0-25 \mathrm{~cm}, 25-$ $50 \mathrm{~cm}, 50-75 \mathrm{~cm}$ and $75-100 \mathrm{~cm}$ depth in agricultural areas and deciduous forests from the nationwide grid sampling programme are published by Rubæk et al. (2013). Total inorganic P (mineral P) was estimated from Bondorff $\mathrm{P}$, in which $\mathrm{P}$ was extracted with $0.2 \mathrm{~N} \mathrm{H}_{2} \mathrm{SO}_{4}$. The Bondorff analysis extracts close to 100 percent of the total inorganic P in soils (Rubæk and Sibbesen, 2000). The soil samples were categorised into seven soil texture classes based on silt, 
clay, fine sand and organic material content, which make up the Danish soil classification system, and measured values for soil $\mathrm{P}, A l_{o x}$ and $F e_{o x}$ were averaged for the soil texture classes. Soil analysis and detailed data are described by Rubæk et al. (2013).

\subsection{SWAT model input and set up}

The SWAT2012 model was set up for the Lillebæk and Kratholm. Topographic data used for catchment delineation were based on a 1.6 m LIDAR DEM resampled to a 16-m-grid DEM (GST, 2010) and a digital stream and tile drain network (Figure 2b). A land use map derived from aerial photos (Pedersen et al., 2010) (Figure 2c), a 250-m grid, three-layer soil map (Greve et al., 2007) (Figure 2d) and three slope classes derived from DEM were used for HRU definition. The TileL1 and TileL2 fields were specified as separate land use types in the Lillebæk catchment, so TileL1 and TileL2 could be represented by their own unique HRU in SWAT. The land use types representing TileL1 and TileL2 were exempted from thresholds of multiple HRU specification. After model delineation and HRU specification, the Lillebæk catchment covered $4.28 \mathrm{~km}^{2}$, had one sub-basin and 3 HRUs, of which two represented TileL1 and TileL2. Catchment delineation and HRU definition at Kratholm was taken from a previous study by Lu et al. (2014) and the catchment covered $486 \mathrm{~km}^{2}$ with 29 sub-basins and 429 HRUs.

Climate data consisted of $10 \mathrm{~km}$-grid daily precipitation data corrected for rain gauge undercatch due to wind effects (Frich et al., 1997), $20 \mathrm{~km}$-grid daily solar radiation and wind speed data (Scharling and Kern-Hansen, 2012), and station-based daily maximum and minimum temperature and relative humidity data (Vilic et al., 2013) from the Danish Meteorological Institute. The spacing of the rain gauges used for deriving the $10 \mathrm{~km}$-grid data is uneven, one station is close to Lillebæk and nine stations are within Kratholm (Scharling and Kern-Hansen, 2012). For both Lillebæk and Kratholm, the new shallow water table method and the Hooghoudt-Kirkman method from Moisasi et al. (2013) were used for tile drain flow simulation. The SCS curve number method $(\mathrm{ICN}=0)$ 
(USDA-SCS, 1972) was used for surface runoff and the Penman-Monteith (Monteith, 1965) method was used for evapotranspiration. In-stream nutrient routing processes were inactivated to focus on the DRP transport at landscape.

The initial soil P content, $A l_{o x}$ and $F e_{o x}$ were derived from the Danish nationwide soil $\mathrm{P}$ inventory. Each SWAT soil type was assigned to a soil texture classes (STCs) in the Danish soil classification system in order to derive initial conditions. The summed $A l_{o x}$ and $F e_{o x}$ of each SWAT soil type was assigned to the mean value of the measurements for the STC. The SWAT model allows the user to initialise labile and organic $\mathrm{P}$, while active inorganic and stable inorganic P are estimated from soil organic matter and clay content (White et al., 2010). Initial labile P value was derived by changing value from 0 to $20 \mathrm{mg} \mathrm{kg}^{-1}$ with increments of $0.1 \mathrm{mg} \mathrm{kg}^{-1}$, after which active $\mathrm{P}$ and stable $\mathrm{P}$ were calculated based on equations from the SWAT model. Next, the summed labile, active and stable P (SWAT soil mineral P) values for each SWAT soil type were compared with the measured soil mineral P of the STC. The value for labile P that gave the SWAT soil mineral P closest to the measured soil mineral P was used as the initial SWAT labile P content. The organic P content was calculated as the measured soil TP minus the SWAT soil mineral P. Input data for the soil P content and oxalate extractable minerals for each SWAT soil type are shown in Table 2.

\subsection{Calibration and sensitivity and uncertainty analysis}

A stepwise calibration of first flow and then DRP load was carried out with Nash-Sutcliffe Efficiency as the objective function. The SWAT2012 model was first calibrated for tile drain flow at TileL1 and TileL2 and stream discharge at Kratholm station. Then with the calibrated flow parameters fixed, the extended SWAT model with DrainP module (DrianP model) was calibrated for tile drain DRP yields at TileL1 and TileL2 and stream DRP yields at Kratholm. The SWAT2012 model was also calibrated for stream DRP yields at Kratholm and compared to the DrainP model. 
The SWAT2012 and DrainP model shared identical streamflow and surface DRP transport parameters, there were but two parameters for DPR leaching in DrainP more than the SWAT2012 model. The SWAT2012 model does not simulate tile drain DRP load and therefore was not compared with the DrainP model at TileL1 or TileL2. To evaluate DrainP module on DRP dynamics, simulated composite DRP concentrations in tile-drained fields and at Kratholm were compared with measured composite orthophosphate concentrations. Simulated composite DRP concentrations were derived from the sum of the simulated DRP loads divided by the sum of the simulated tile drain flow during the sampling days.

Parameters and ranges for tile drain flow and stream discharge were selected and defined after manual calibration (Table 3). The parameter ranges were set so that the simulated annual water budgets were realistic, following guidance from Arnold et al. (2012). In TileL1 and TileL2, only tile drain flow was calibrated, therefore parameters not related to tile drain flow, like ALPHA_BF, GW_DELAY and RCHRG_DP etc., were not calibrated. For tile drain DRP and stream DRP loads, DrainP parameters ranges were defined from literature. Nelson and Parsons (2006) estimated $k_{L}$ from measured reversibly adsorbed P and DRP concentrations in loamy soils receiving swine slurry and found that $k_{L}$ ranged from 0.5 to $2.4 \mathrm{l} \mathrm{mg}^{-1}$. Schoumans et al. (2013) conducted an uncertainty analysis of $k_{L}$ and $\beta_{m}$ for P leaching in Dutch sandy soils and found that $\beta_{m}$ varied from 0.06 to 0.23.

The impact of the DrainP module on the SWAT model was evaluated by sensitivity and uncertainty analysis of the new parameters $k_{L}$ and $\beta_{m}$ on DRP transport in tile-drained fields and at Kratholm. Calibration, sensitivity and uncertainty analysis were carried out with the Sequential Uncertainty Fitting Algorithm (SUFI2) in SWAT Calibration and Uncertainty Procedures (SWATCUP) (Abbaspour et al., 2007). In SUFI2, the parameter sensitivity was measured with a t-test, where higher absolute $t$-Stat values indicated more sensitivity, and a P-value determining the significance of the sensitivity. Parameter uncertainties were given with a 95\% prediction 
uncertainty (95PPU) band around the best simulation. SUFI2 quantifies the 95PPU with two factors: the percentage of observations included in the 95PPU (P-factor) and the average thickness of the 95PPU band (R-factor). An ideal model would have a P-factor of 1 and an R-factor of 0. SUFI2 only accounts for prediction uncertainties from the calibration parameters. Other uncertainties from model structure, input data and measured observations etc. are not included. The models were run from 1989 to 1997 for warm up, from 1998 to 2002 for calibration and from 2003 to 2006 for validation. Calibrations of the tile drain flow and stream discharge parameters were run for 1000 iterations, whereas sensitivity, uncertainty analysis and calibration of tile drain and stream DRP load parameters in the DrainP module were run for 500 iterations.

\section{Results}

\subsection{SWAT2012 for tile drain and stream flow}

The SWAT2012 model simulated well the monthly tile drain flow yield in in the monitored tiledrained fields TileL1 and TileL2 (Figure 3a and b) and stream discharge at the Kratholm station (Figure 3c). The SWAT model captured the seasonal variation of observed tile drain flow - active in winter and inactive in summer in both TileL1 and TileL2, though the simulated onset of tile drain flow occurred earlier than the observations in both 2000 and 2001 (Figure 3a and b). The NashSutcliffe efficiency (NSE) and the percent bias (PBIAS) confirmed that the simulated tile drain flows are "very good" and "good" during calibration and remain "good" and increase to "very good" during validation relative to the criteria defined for stream flow by Moriasi et al. (2007).

\subsection{DrainP for tile drain and catchment DRP yields and concentrations}

The extended SWAT model with the DrainP module (DrainP model) simulated well the monthly DRP yields in TileL1 (Figure 4a) despite mismatches in 2000 and 2001 due to the early onset of the 
simulated tile drain flow (Figure 3a). The NSE and PBIAS indicated that the simulated DRP yields in TileL1 were "satisfactory" during calibration and increased to "good" during validation. In TileL2, the DrainP model missed the peak in winter 2001 during calibration and two peaks in 2004 during validation (Figure 4b), when the field was turned into grassland without tillage (Appendix), and the simulated DRP yields did not match the observations as well as in TileL1.

The DrainP model simulated the monthly DRP transport much better than the SWAT2012 model at the Kratholm station (Figure 4c). The DrainP model captured the catchment DRP peaks very well during winter when tile drains were active, whereas the SWAT2012 model missed all the peaks. However, both the DrainP and the SWAT model underestimated the DRP transport during summer when the tile drains were inactive. Calibrated DRP yields were higher than the upper limit of 95PPU band, indicating high tile drain DRP yields to the streams. The 95PPU band of the simulated DRP yields at Kratholm did not cover the observations, indicates a systematic underestimation. The NSE and PBIAS confirmed that simulations by the DrainP model were better than those of the SWAT2012 model, even though they were still somewhat less than the observed DRP yields.

The composite DRP concentrations in the tile-drained fields simulated by the DrainP model matched well the observed ones (Figure 5a), even though observed DRP concentrations higher than $0.2 \mathrm{mg} \mathrm{P} \mathrm{l}^{-1}$ were not captured by the DrainP model. On the other hand, at the Kratholm station, the simulated DRP concentrations from the DrainP model were higher and much less biased than those simulated by the SWAT2012 model (Figure 5b).

\subsection{Impact of DrainP on the SWAT model}

Except $k_{L}$ in TileL1, both tile drain and stream DRP yields were sensitive to the DrainP parameters $k_{L}$ and $\beta_{m}$ with P-values less or close to 0.001 , which indicate significant sensitivity.

(Table 4). However, the absolute $t$-Stat value, which measures the level of sensitivity, at Kratholm was higher than in the tile-drained fields, indicating DrainP parameters are more sensitive to DRP 
transport at the catchment scale than in tile-drained fields. t-Stat evaluates changes of the objective function with parameters, and DrainP improved the objective function NSE at Kratholm (0.8 in Figure 4c) more than at the tile-drained fields $(<0.6)$, and therefore DrainP parameters were more sensitive for catchment DRP yields. On the other hand, the 95\% prediction uncertainty (95PPU) band of DrainP at Kratholm (R-factor 0.35) was similar to the tile-drained fields (R-factor 0.31 and 0.12) (Figure 4). In other words, the overall DRP yield at the catchment scale was more sensitive to the DrainP module than the tile drain DRP yields in the tile-drained fields, while the uncertainties were similar.

The DrainP model changed the overall source allocation of the simulated DRP transport at the Kratholm station. In the SWAT2012 model, groundwater contributed 55\% of the simulated DRP transport, though it contributed less than half to the stream flow, and the tile drains contributed 38\% to the stream flow and did not contribute at all to the DRP transport (Table 5). After inclusion of the DrainP module, tile drains contributed the most to the simulated DRP transport at the Kratholm station, followed by groundwater. Point sources contributed the least to the simulated DRP transport in both the SWAT and DrainP module during the study period of 1998 to 2006.

\subsection{Soil phosphorus accumulation and budget}

The simulated soil total P (TP) in the top $30 \mathrm{~cm}$ soil layer increased in both the tile-drained fields (Figure 6a) and in the River Odense catchment (Figure 6b). However, the increases in the tiledrained fields (Figure 6a) compared to the initial TP content in 1989 were higher and more dynamic than in the River Odense catchment (Figure 6b). Moreover, the soil TP content in the tillage layer in TileL1 and TileL2 also varied and exhibited very different patterns (Figure 6a) despite identical initial conditions. The simulated TP increase at 0-30 cm depth from 1989 to 1998 in the study areas (first columns in Figure 6a and b) were close to the mean values of the measured soil TP increase 
from 1986 to 1998 for the soil texture classes (STCs) assigned to the SWAT soil types at 0-25 cm depth (red dots in Figure 6a and b).

The simulated accumulation of TP in the soil profile was mainly due to the excess input of P fertilizers compared to the P yields (Figure 7). The average annual P inputs from 1998 to 2006, mainly as animal manure (Table 1), were much higher than the total P export from the fields in both the tile-drained fields and in Kratholm. The total P export is the sum of P export with harvested crops and a minor contribution from total P lost through surface runoff, tile drain flow and leaching out of the soil profile. The P fertilizer data at Kratholm (Figure 7c) were derived from 2005 general statistics and showed lower annual P fertilizer application than at the tile-drained fields (Figure 7a and 7b). Still the simulated soil TP in River Odense catchment increased at an annual rate of around $15 \mathrm{~kg} \mathrm{P} \mathrm{ha}{ }^{-1}$.

\section{Discussion}

\subsection{Simulated flow and DRP at the field and catchment scale}

The SWAT2012 model simulated very well the monthly tile drain discharge in the tile-drained fields TileL1 and TileL2, even though the two fields exhibit great temporal variability. Studies that simulate sub-daily or daily tile drain discharge typically require on-site sub-daily precipitation observations, location and spacing of tile drain pipes and a detailed description of soil properties (Arabi et al., 2006; Tiemeyer et al., 2007; Branger et al., 2009). Such detailed information were not available in this study: precipitation data were daily aggregated grid data, tile drain installation depths and spacing were calibrated and the soil data had a 250 m-resolution. With similar model input data, the simulated daily tile drain discharge in TileL1 and other tile-drained fields in the Lillebæk catchment from the fully distributed MIKE-SHE model coupled with the Daisy model were "unsatisfactory" (NSE < 0.2) (Hansen et al. 2012). 
The DrainP module captured the seasonal dynamics of DRP yields in the tile-drained fields. In our study, the Nash-Sutcliffe Efficiencies of simulated tile drain DRP yields were close to the findings in a study simulating bi-weekly DRP transport using the CREAMS model (Larsson et al., 2007). On the other hand, DrainP missed the major peak events in both tile-drained fields and could not simulate the tile drain DRP concentrations higher than $0.2 \mathrm{mg} \mathrm{P} \mathrm{l}^{-1}$, probably due to a lack of a macropore flow component. The observed DRP yields peaked in TileL2 when it was turned into grassland for 2 to 3 years with no tillage (Table 1 and Appendix). Zhang et al. (2015) found that in continuous grassland without tillage, DRP concentrations in tile drains were higher than the ones with tillage, probably due to better macropore connectivity. Other studies have also found an increased transport of soluble tracer and pesticide out of the soil in no tillage fields compared to fields with tillage (Malone et al., 2014; Petersen et al., 2004). Therefore, there might be more preferential transport via macropores in TileL2 during the years without tillage. Many studies have shown that water and P concentrations may peak in tile drains during storm events via macropore transport (Iversen et al., 2011; Ball Coelho et al., 2012). However, the DrainP model lacks the macropore transport component and therefore could not generate the peak concentrations. As a result, the DrainP module might overestimate DRP concentrations in lower soil layers in order to compensate the lack of macropore transport. Moreover, studies have shown that both the soil $\mathrm{P}$ content in the root zone and the presence of shallow groundwater have a significant impact on the DRP concentrations in tile drains (Heckrath et al., 1995; Gachter et al., 1998; Vadas et al. 2007). Therefore, the lack of on-site soil P measurements and the lack of interaction with groundwater in DrainP may decrease the ability to simulate dynamic DRP concentrations.

The DrainP module enabled the SWAT model to simulate DRP transport from tile drains, and thereby generated higher DRP yields and improved the simulated DRP transport at the Kratholm station. Moreover, the DrainP module changed the source allocation of DRP transport at the 
catchment scale. After including the DrainP module, tile drains contributed most (46\%) of the simulated DRP yields at Kratholm and second most (38\%) of the stream flow after groundwater. According to a review by King et al. (2014b), tile drain flow may contribute from $40 \%$ up to $80 \%$ of the stream flow, but typically only $16 \%$ to $58 \%$ of the DRP yields in tile-drained agricultural catchments. The simulated tile drain contribution to stream flow and DRP yields at Kratholm fell within this range. The relative importance of the tile drain contribution depends, however, on the magnitude of other sources, e.g. point sources. The P input from point sources in Denmark has been reduced by more than $80 \%$ since 1990 (Wiberg-Larsen et al., 2015), thus the relative importance of the tile drain component has increased over time.

The SWAT2012 model generally underestimated the DRP yields at Kratholm, though we found less underestimation when including the DrainP module. However, the DrainP model still systemically underestimated DRP yields, indicating that the model is missing processes that cannot be compensated for by calibration. The missing processes might include in-stream nutrient routing processes, that might be important for DRP yields (van der Perk et al., 2006), as the in-stream processes were inactivated to focus on the DRP transport at landscape. There is a risk that the differences between simulated and observed values were compensated for by the calibration of DRP yields from tile drains, which might not be realistic. Therefore, DRP leaching experiments should ideally be conducted to further validate DrainP parameters $\left(k_{L}\right.$ and $\left.\beta_{m}\right)$ from the Langmuir isotherm, in order to avoid overestimation of tile-drain DRP yields. This requires, though, extensive work at the catchment scale due to the great heterogeneity in soil properties.

\subsection{Soil phosphorus accumulation}

The simulated soil total phosphorus (TP) matched the observed general soil TP accumulation in Danish agricultural areas. Rubæk et al. (2013) reported that soil TP increased between 1986 and 1998 in lighter soil textures (STC 1-5), whereas soil TP in heavier soil textures (STC 6-7) remained 
unchanged or decreased. They also reported that the increase of measured soil TP at 0-25 cm depth was positively correlated with the amount of applied animal manure. The simulated TP accumulation in the plough layer was also driven by animal manure input. The accumulated TP increase varied greatly between fields and among years in the tile-drained fields, where the management practices, including fertilizer type and application rates, were based on on-site interviews and varied from year to year (Table 1). In contrast, for the River Odense catchment, 5year crop rotations were based on agricultural statistics for 2005 (Lu et al., 2014). Thus, the accumulated TP increases were more stable and exhibited a repeated pattern for every 5 years.

TP accumulation due to extensive animal manure input is common worldwide (McLaughlin et al., 2011; Jiang et al., 2013), which increases the risk of P leaching and may damage the ecosystems of the receiving waters (Bennett et al., 2001). In order to reduce the risk, nationwide nutrient loss regulations were initiated in the 1980s. The estimated P surplus in Denmark has declined from around $20 \mathrm{~kg} \mathrm{P} \mathrm{ha}^{-1} \mathrm{y}^{-1}$ in late 1980 to around $4 \mathrm{~kg} \mathrm{P} \mathrm{ha}^{-1} \mathrm{y}^{-1}$ in 2010 (Vinther and Olsen, 2011). However, the effect of rapidly declined P surplus on soil TP accumulation requires crop managements with declined fertilizer application rates over time. In our study, P fertilizer application at the tile-drained fields (Table 1) and Kratholm (constant) did not follow the decline trend during the study period.

\section{Conclusion}

The SWAT2012 model extension DrainP for dissolved reactive phosphorus (DRP) transport from tile drains simulated well the monthly DRP transport in the tile-drained fields and substantially improved the simulation of monthly DRP transport and changed the overall source allocation at the catchment scale. In order to avoid overestimation of tile-drain DRP yields, DrainP parameters in the Langmuir isotherm should ideally be validated with DRP leaching experiments. 
The DrainP model lacks a macropore transport component and this could be partly responsible for the inability to reproduce peak DRP concentrations in tile drain flow. Macropores can transport fine sediment and particulate and other forms of phosphorus to the tile drains and further to the receiving waters. Therefore, future relevant work include analysis of the potentials for macropore and other forms of phosphorus transport from tile drains to surface waters.

\section{Acknowledgement}

We would like to thank Prof. Raghavan Srinivasan for inviting the corresponding author to stay at Texas A\&M University and advising us on model development and calibration. We would also like to thank Dr. Jeffrey G. Arnold and his colleagues at the Grassland Soil and Water Research Laboratory, USDA-ARS, for their contribution to the model development. The comments from anonymous reviewers helped us to improve the conceptual model and simulation results. Our colleagues Gitte Blicher-Mathiesen and Ruth Grant provided valuable catchment information and observation data. We are grateful to Anne Mette Poulsen for language assistance. The study was sponsored by the IMAGE project funded by the Danish Strategic Research Council (09-067259).

\section{References}

Abbaspour K.C., Yang J., Maximov I., Siber R., Bogner K., Mieleitner J., Zobrist J., Srinivasan R., 2007. Modelling hydrology and water quality in the pre-alpine/alpine Thur watershed using SWAT. J. Hydrol. 333, 413-430. DOI: 10.1016/j.jhydrol.2006.09.014.

Arabi M., Stillman J.S., Govindaraju R.S., 2006. A process-based transfer function approach to model tile-drain hydrographs. Hydrol. Process. 20, 3105-3117. DOI: 10.1002/hyp.6153. 
Arnold J.G., Srinivasan R., Muttiah R.S., Williams J.R., 1998. Large area hydrologic modeling and assessment - Part 1: Model development. J. Am. Water Resour. Assoc. 34, 73-89. DOI: 10.1111/j.1752-1688.1998.tb05961.x.

Arnold J.G., Moriasi D.N., Gassman P.W., Abbaspour K.C., White M.J., Srinivasan R., Santhi C., Harmel R.D., van Griensven A., Van Liew M.W., Kannan N, Jha M.K., 2012. SWAT: Model use, calibration and validation. Trans. ASABE. 55, 1491-1508.

Ball Coelho B., Murray R., Lapen D., Topp E., Bruin A., 2012. Phosphorus and sediment loading to surface waters from liquid swine manure application under different drainage and tillage practices. Agr. Water. Manage. 104, 51-61. DOI: 10.1016/j.agwat.2011.10.020.

Bennett E.M., Carpenter S.R., Caraco N.F., 2001. Human impact on erodable phosphorus and eutrophication: a global perspective increasing accumulation of phosphorus in soil threatens rivers, lakes, and coastal oceans with eutrophication. BioScience. 51, 227-234.

Bicknell B.R., Imhoff J.C., Kittle J.L.Jr., Donigian A.S.Jr., Johanson R.C., 1997. Hydrological Simulation Program-Fortran, User's manual for version 11. US EPA, National Exposure Research Laboratory. http://water.usgs.gov/software/HSPF/ (accessed 11 Nov 2015)

Blann K.L., Anderson J.L., Sands G.R., Vondracek B., 2009. Effects of Agricultural Drainage on Aquatic Ecosystems: A Review. Crit. Rev. Env. Sci. Tech. 39, 909-1001. DOI: 10.1080/10643380801977966.

Branger F., Tournebize J., Carluer N., Kao C., Braud I., Vauclin M., 2009. A simplified modelling approach for pesticide transport in a tile-drained field: The PESTDRAIN model. Agr. Water. Manage. 96, 415-428. DOI: 10.1016/j.agwat.2008.09.005.

Brevé MA., Skaggs R.W., Parsons J.E., Gilliam J.W., 1997. DRAINMOD-N, a nitrogen model for artificially drained soils. Trans. ASAE. 40, 1067-1075. 
Carpenter, S.R. et al., 1998. Nonpoint pollution of surface waters with phosphorus and nitrogen. Ecol. Appl., 8(3): 559-568.

Correll D.L., 1998. The role of phosphorus in the eutrophication of receiving waters: A review. J. Environ. Qual. 27, 261-266.

Dils R.M., Heathwaite A.L., 1999. The controversial role of tile drainage in phosphorus export from agricultural land. Water Sci. Technol. 39, 55-61. DOI: 10.1016/S0273-1223(99)003182

Ekholm P., Turtola E., Grönroos J., Seuri P., Ylivainio K., 2005. Phosphorus loss from different farming systems estimated from soil surface phosphorus balance. Agr. Ecosys. Environ. 110, 266-278. DOI: 10.1016/j.agee.2005.04.014.

Frich P., Rosenørn S., Madsen H., Jensen J.J., 1997. Observed precipitation in Denmark, 1961-90. Technical report 97-8. http://www.dmi.dk/fileadmin/user_upload/Rapporter/TR/1997/tr978.pdf (accessed 16 Nov 2015)

Gachter R., Ngatiah J.M., Stamm C., 1998. Transport of Phosphate from Soil to Surface Waters by Preferential Flow. Environ. Sci. Tech. 32, 1865-1869. DOI: 10.1021/es9707825.

Greve M.H., Greve M.B., Bøcher P.K., Balstrøm T., Breuning-Madsen H., Krogh L., 2007. Generating a Danish raster-based topsoil property map combining choropleth maps and point information. Geografisk Tidsskrift. 107, 1-12.

Hansen A.L., Refsgaard J.C., Christensen B.S.B., Jensen K.H., 2013. Importance of including small-scale tile drain discharge in the calibration of a coupled groundwater-surface water catchment model. Water Resour. Res. 49, 585-603. DOI: 10.1029/2011WR011783.

Haygarth P.M., Hepworth L., Jarvis .SC., 1998. Forms of phosphorus transfer in hydrological pathways from soil under grazed grassland. Eur. J. Soil Sci. 49, 65-72. DOI: 10.1046/j.1365-2389.1998.00131.x. 
Heathwaite A.L., Dils R.M., 2000. Characterising phosphorus loss in surface and subsurface hydrological pathways. Sci. Total Environ. 251-252, 523-538. DOI: 10.1016/S00489697(00)00393-4.

Heckrath G., Brookes P.C., Poulton P.R., Goulding K.W.T., 1995. Phosphorus leaching from soils containing different phosphorus concentrations in the broadbalk experiment. J. Environ. Qual. 24, 904-910.

Iversen B.V., Børgesen C.D., Lægdsmand M., Greve M.H., Heckrath G., Kjærgaard C., 2011. Risk predicting of macropore flow using pedotransfer functions, textural Maps, and Modeling. Vadose Zone J. 10, 1185-1195. DOI: 10.2136/vzj2010.0140.

Jiang P., Meng C., Wu J., Chen W., Xu K., Xu Q., 2013. Accumulation and Leaching Risk of Soil Phosphorus in Lei Bamboo Stands in the Upper Reaches of Taihu Lake. American-Eurasian J. Agric. \& Environ. Sci. 13, 891-900. DOI: 10.5829/idosi.aejaes.2013.13.07.2006.

Kiesel J., Fohrer N., Schmalz B., White M.J., 2010. Incorporating landscape depressions and tile drainages of a northern German lowland catchment into a semi-distributed model. Hydrol. Process. 24, 1472-1486.

King K.W., Williams M.R., Fausey N.R., 2014a. Contributions of Systematic Tile Drainage to Watershed-Scale Phosphorus Transport. J. Environ. Qual. In press. DOI: 10.2134/jeq2014.04.0149.

King K.W., Williams M.R., Macrae M.L., Fausey N.R., Frankenberger J., Smith D.R., Kleinman P.J.A., Brown L.C., 2014b. Phosphorus Transport in Agricultural Subsurface Drainage: A Review. J. Environ. Qual. In press. DOI: 10.2134/jeq2014.04.0163.

Kleinman P.J.A., Smith D.R., Bolster C.H., Easton Z.M., 2015. Phosphorus Fate, Management and Modeling in Artificially Drained Systems. J. Environ. Qual. 44, 460-466. DOI: 10.2134/jeq2015.02.0090. 
GST Danish Geodata Agency. 2010. Danmarks Højdemodel: DHM Terraen National Survey and Cadastre. Copenhagen.

Koch S., Bauwe A., Lennartz B., 2013. Application of the SWAT Model for a Tile-Drained Lowland Catchment in North-Eastern Germany on Subbasin Scale. Water Resour. Manag. 27, 791-805. DOI: 10.1007/s11269-012-0215-X.

Kronvang B., Laubel A., Grant R., 1997. Suspended sediment and particulate phosphorus transport and delivery pathways in an arable catchment, Gelbæk stream, Denmark. Hydrol. Process. 11, 627-642. DOI: 10.1002/(SICI)1099-1085(199705)11:6<627::AID-HYP481>3.0.CO;2-E.

Kronvang B., Vagstad N., Behrendt H., Bøgestrand J., Larsen S.E., 2007. Phosphorus losses at the catchment scale within Europe: an overview. Soil Use Manage. 23, 104-116. DOI: 10.1111/j.1475-2743.2007.00113.x.

Lam Q.D., Schmalz B., Fohrer N., 2011. The impact of agricultural Best Management Practices on water quality in a North German lowland catchment. Environ. Moni. Assess. 183, 351-379. DOI: 10.1007/s10661-011-1926-9.

Lam Q.D., Schmalz B., Fohrer N., 2012. Assessing the spatial and temporal variations of water quality in lowland areas, Northern Germany. J. Hydrol. 438-439, 137-147. DOI: 10.1016/j.jhydrol.2012.03.011.

Larsson M.H., Jarvis N.J., 1999. Evaluation of a dual-porosity model to predict field-scale solute transport in a macroporous soil. J. Hydrol. 215, 153-171. DOI: 10.1016/S00221694(98)00267-4.

Larsson M.H., Persson K., Ulén B., Lindsjö A., Jarvis N.J., 2007. A dual porosity model to quantify phosphorus losses from macroporous soils. Ecol. Model. 205, 123-134. DOI: 10.1016/j.ecolmodel.2007.02.014. 
Lu S., Kronvang B., Audet J., Trolle D., Andersen H.E., Thodsen H., van Griensven A., 2014. Modelling sediment and total phosphorus export from a lowland catchment: comparing sediment routing methods. Hydrol. Process. in press. DOI:10.1002/hyp.10149.

Malone R.W., Nolan B.T., Ma L., Kanwar R.S., Pederson C., Heilman P., 2014. Effects of tillage and application rate on atrazine transport to subsurface drainage: Evaluation of RZWQM using a six-year field study. Agr. Water Manage. 132, 10-22. DOI:

10.1016/j.agwat.2013.09.009.

McLaughlin M., McBeath T., Smernik R., Stacey S., Ajiboye B., Guppy C., 2011. The chemical nature of $\mathrm{P}$ accumulation in agricultural soils_-implications for fertiliser management and design: an Australian perspective. Plant Soil. 349, 69-87. DOI: 10.1007/s11104-011-0907-7.

Monteith J.L., 1965. Evaporation and environment. In Symposia of the Society for experimental biology. 19, 205-234.

Moriasi D.N., Arnold J.G., Van Liew M.W., Bingner R.L., Harmel R.D., Veith T.L., 2007. Model evaluation guidelines for systematic quantification of accuracy in watershed simulations. Trans. ASABE. 50, 885-900.

Moriasi D.N., Arnold J.G., Vazquez-Amábile G.G., Engel B.A., 2011. Shallow water table depth algorithm in Swat: Recent developments. Trans. ASABE. 54, 1705-1711.

Moriasi D.N., Gowda P.H., Arnold J.G., Mulla D.J., Ale S., Steiner J.L., Tomer M.D., 2013. Evaluation of the hooghoudt and kirkham tile drain equations in the soil and water assessment tool to simulate tile flow and nitrate-nitrogen. J. Environ. Qual. 42, 1699-1710.

Murphy J., Riley J., 1962. A modified single solution method for the determination of phosphate in natural waters. Anal. chim. acta. 27, 31-36.

Neitsch S.L., Arnold J.G., Kiniry J.R., Williams J.R., 2011. Soil and Water Assessment Tool Theoretical Documentation Version 2009. Texas Water Resources Institute. College Station. 
Nelson N.O., Parsons J.E., 2006. Modification and Validation of GLEAMS for Prediction of Phosphorus Leaching in Waste-Amended Soils. Trans. ASABE. 49(1251-1387), 1395-1407.

Olesen S.E., 2009. Kortlægning af potentielt dræningsbehov på landbrugsarealer opdelt efter landskabselement, geologi, jordklasse, geologisk region samt høj/lavbund. Det Jordbrugsvidenskabelige Fakultet, Aarhus Universistet. Tejle, Danmark.

Pedersen L.E., Blicher-Mathiesen G., Mejlhede P., Grant R., 2010. Oplandsmodellering af vand og kvælstof i umættet zone for oplandet til lillebæk. Danmarks Miljøundersøgelser. Silkeborg.

Petersen C.T., Hansen S., Jensen H.E., Holm J., Koch C.B., 2004. Movement of suspended matter and a bromide tracer to field drains in tilled and untilled soil. Soil Use Manage. 20, 271-280. DOI: 10.1111/j.1475-2743.2004.tb00368.x.

Radcliffe D.E., Reid D.K., Blombäck K., Bolster C.H., Collick A.S., Easton Z.M., Francesconi W., Fuka D.R., Johnsson H., King K., Larsbo M., Youssef M.A., Mulkey A.S., Nelson N.O., Persson K., Ramirez-Avila J.J., Schmieder F., Smith D.R., 2015. Applicability of Models to Predict Phosphorus Losses in Drained Fields: A Review. J. Environ. Qual. 44, 614-628. DOI: 10.2134/jeq2014.05.0220.

Rossi C.G., Heil D.M., Bonumà N.B., Williams J.R., 2012. Evaluation of the Langmuir model in the Soil and Water Assessment Tool for a high soil phosphorus condition. Environmental Modell. Softw. 38, 40-49. DOI: 10.1016/j.envsoft.2012.04.018.

Rubæk G.H., Kristensen K., Olesen S.E., Østergaard H.S., Heckrath G., 2013. Phosphorus accumulation and spatial distribution in agricultural soils in Denmark. Geoderma. 209-210, 241-250. DOI: 10.1016/j.geoderma.2013.06.022.

Rubæk G.H., Sibbesen E., 2000. Long-term phosphorus fertilisation - Effects on crop yield and soil phosphorus status. DIAS report n. 31. Plant Production. Danish Institue of Agricultural Sciences. 43 pages. 
Russell M.A., Walling D.E., Hodgkinson R.A., 2001. Suspended sediment sources in two small lowland agricultural catchments in the UK. J. Hydro. 252, 1-24. DOI: 10.1016/S00221694(01)00388-2.

Scharling M., Kern-Hansen C., 2012. Climate Grid Denmark. Dataset for use in research and education. Daily and montly values 1989-2010. Danish Meteorological Institute. Technical Repoart 12-10. Copenhagen. http://beta.dmi.dk/fileadmin/Rapporter/TR/tr12-10.pdf (accessed 16 Nov 2015)

Schmalz B., Tavares F., Fohrer N., 2007. Assessment of nutrient entry pathways and dominating hydrological processes in lowland catchments. Adv. Geosci. 11, 107-112.

Schoumans O.F., Van der Salm C., Groenendijk P., 2013. PLEASE: a simple model to determine P losses by leaching. Soil Use Manage. 29, 138-146. DOI: 10.1111/sum.12008.

Sharpley A.N., Chapra S.C., Wedepohl R., Sims J.T., Daniel T.C., Reddy K.R., 1994. Managing agricultural phosphorus for protection of surface waters: Issues and options. J. Environ. Qual. 23, 437-451.

Simard R.R., Beauchemin S., Haygarth P.M., 2000. Potential for preferential pathways of phosphorus transport. J. Environ. Qual. 29, 97-105.

Smedema L.K., Abdel-Dayem S., Ochs W.J., 2000. Drainage and agricultural development. Irrig. Drain. System. 14, 223-235.

Šimůnek J., van Genuchten M.Th., Šejna M., 2008. Development and applications of the HYDRUS and STANMOD software packages and related codes. Vadose Zone J. 7,587-600. DOI: 10.2136/vzj2007.0077.

Steglich E. and Williams J.R., 2013. Agricultural Ploicy/Extension eXtender: User manual version 0806. Blackland Research and Extension Center. http://apex.tamu.edu/media/71997/apex0806-user-guide.pdf (accessed 11 November 2015) 
Tiemeyer B., Moussa R., Lennartz B., Voltz M., 2007. MHYDAS-DRAIN: A spatially distributed model for small, artificially drained lowland catchments. Ecol. Model. 209, 2-20. DOI: 10.1016/j.ecolmodel.2007.07.003.

USDA-SCS, 1972. Soil Convervation Service Section IV: Hydrology, National Engineering Handbook. US Department of Algriculture, pp. 4-102.

Vadas P.A., Srinivasan M.S., Kleinman P.J.A, Schmidt J.P., Allen A.L., 2007 Hydrology and groundwater nutrient concentrations in a ditch-drained agroecosystem. J. Soil Water Conserv. 62(4),178-188.

Vadas P.A., White M.J., 2010. Validating soil phosphorus routines in the SWAT model. Trans. ASABE. 53, 1469-1476.

Van der Perk M., Owens P.N., Deeks L.K., Rawlins B.G., 2006. Streambed sediment geochemical controls on in-stream phosphorus concentrations during baseflow. Water Air Soil Pollut: Focus. 6,443-451. DOI: 10.1007/s11267-006-9058-x.

Van der Zee S.E.A.T.M., Van Riemsdijk W.H., 1988. Model for long-term teaction kinetics in animal manure polluted soils J. Environ. Qual. 17, 35-41.

Van der Zee S.E.A.T.M., Bolt G.H., 1991. Deterministic and stochastic modeling of reactive solute transport. J. Contam. Hydrol. 7(1-2), 75-93.

Vilic K., Kern-Hansen C., Hansen J.Q., Jensen J., 2012. Catalogue of Meteorological Stations in Denmark. Technical Report 12-12. Danish Meteorological Institute. Copenhagen. http://beta.dmi.dk/fileadmin/Rapporter/TR/tr12-12.pdf (accessed 18 Nov 2015)

Vinther F.P., Olsen P., 2011. Nutrient balances and nutrient surpluses in Danish agriculture 19892009 (2010). Department of Agroecology, Aarhus Univerisity. http://pure.au.dk/portal/files/44001426/803795_NPK_balances_in_DK_1989_2009.pdf (accessed 18 Nov 2015) 
White M.J., Storm D.E., Busteed P.R., Smolen M.D., Zhang H., Fox G.A., 2010. A quantitative phosphorus loss assessment tool for agricultural fields. Environmental Modell. Softw. 25, 1121-1129.

Wiberg-Larsen P., Windolf J., Bøgestrand J., Larsen S.E., Thodsen H., Ovesen N.B., Bjerring R., Kronvang B., Kjeldgaard A., 2015. Vandløb 2013. NOVANA. Aarhus Universitet, DCE Nationalt Center for Miljø og Energi, 50. Technical Report from DCE - Nationalt Center for Miljø og Energi nr. 121 http://dce2.au.dk/pub/SR121.pdf (accessed 20 Sep 2015)

Xue Y., David M.B., Gentry L.E., Kovacic D.A., 1998. Kinetics and modeling of dissolved phosphorus export from a tile- drained agricultural watershed. J. Environ. Qual. 27, 917-922. Zhang T.Q., Tan C.S., Zheng Z.M., Drury C.F., 2015. Tile Drainage Phosphorus Loss with LongTerm Consistent Cropping Systems and Fertilization. J. Environ. Qual. 44, 503-511. DOI: 10.2134/jeq2014.04.0188. 


\section{Appendix}

Crop, date of agricultural activities and applied fertilizers equivalent to mineral nitrogen $(\mathrm{N})$ and phosphorus (P) in the monitored tile-drained fields TileL1 and TileL2 in the Lillebæk catchment.

\begin{tabular}{|c|c|c|c|c|c|c|c|c|c|}
\hline \multicolumn{2}{|l|}{ TileL1 } & \multicolumn{4}{|c|}{ Management date } & \multicolumn{4}{|c|}{ Fertilizer amount } \\
\hline \multirow[t]{2}{*}{ Year } & \multirow[t]{2}{*}{ Crop } & \multirow{2}{*}{ sow } & \multirow[t]{2}{*}{ harvest } & \multirow{2}{*}{ plough } & \multirow{2}{*}{ fertilizer } & \multicolumn{2}{|c|}{ Mineral } & \multicolumn{2}{|c|}{ Manure } \\
\hline & & & & & & $\begin{array}{l}\mathrm{N}(\mathrm{kg} \mathrm{N} \\
\left.\mathrm{ha}^{-1}\right)\end{array}$ & $\begin{array}{l}\text { P (kg P } \\
\left.\text { ha }^{-1}\right)\end{array}$ & $\begin{array}{l}\text { N (kg N } \\
\left.\mathrm{ha}^{-1}\right)\end{array}$ & $\begin{array}{l}\mathrm{P}(\mathrm{kg} P \\
\left.\mathrm{ha}^{-1}\right)\end{array}$ \\
\hline \multirow[t]{4}{*}{ 1997/1998 } & Winter grass & 8/16/1997 & 8/10/1998 & 8/15/1997 & 9/29/1997 & & & 182.3 & 58.4 \\
\hline & & & & & 3/24/1998 & 28 & & & \\
\hline & & & & & 3/25/1998 & 84 & & & \\
\hline & & & & & 4/26/1998 & 42 & & & \\
\hline \multirow[t]{5}{*}{ 1998/2000 } & Grass & 8/11/1998 & 8/6/1999 & 8/11/1998 & 8/11/1998 & 35 & & & \\
\hline & & & 10/20/1999 & & 4/1/1999 & 70 & 13.1 & & \\
\hline & & & 8/9/2000 & & 4/14/1999 & 7 & & & \\
\hline & & & & & 3/30/2000 & & & 131.3 & 37.7 \\
\hline & & & & & 4/7/2000 & 45 & & & \\
\hline \multirow{2}{*}{ 2000/2001 } & Winter wheat & $9 / 15 / 2000$ & 8/19/2001 & $9 / 15 / 2000$ & $4 / 14 / 2001$ & 83.9 & & & \\
\hline & & & & & 5/9/2001 & & & 125.2 & 35.5 \\
\hline \multirow[t]{2}{*}{ 2001/2002 } & Winter wheat & 9/29/2001 & 8/19/2002 & 9/29/2001 & $4 / 11 / 2002$ & 67 & & & \\
\hline & & & & & 5/9/2002 & & & 160.8 & 48.3 \\
\hline 2003 & Spring barley & $3 / 28 / 2003$ & 8/20/2003 & 10/26/2002 & $4 / 25 / 2003$ & 87 & & & \\
\hline \multirow[t]{2}{*}{ 2003/2004 } & Grass & $8 / 21 / 2003$ & $5 / 1 / 2004$ & $9 / 12 / 2004$ & $3 / 28 / 2004$ & 34 & & & \\
\hline & & & & & 4/1/2004 & & & 127.9 & 34.5 \\
\hline \multirow[t]{2}{*}{ 2004/2005 } & Winter wheat & $9 / 12 / 2004$ & $7 / 21 / 2005$ & 8/9/2005 & 4/5/2005 & 43.19 & & & \\
\hline & & & & & $4 / 20 / 2005$ & & & 137.5 & 35.5 \\
\hline \multirow[t]{2}{*}{2006} & Spring barley & 8/10/2005 & $7 / 27 / 2006$ & 9/21/2006 & 4/12/2006 & 28.14 & & & \\
\hline & & & & & $4 / 24 / 2006$ & & & 185 & 46 \\
\hline \multicolumn{10}{|l|}{ TileL2 } \\
\hline 1998 & Sugar beet & 4/14/1998 & 9/30/1998 & $3 / 26 / 1998$ & $\begin{array}{l}3 / 25 / 1998 \\
5 / 18 / 1998\end{array}$ & 27 & & 179 & 34 \\
\hline \multirow[t]{2}{*}{1999} & Spring barley & 4/11/1999 & 7/18/1999 & 3/29/1999 & 3/29/1999 & & & 76 & 12 \\
\hline & & & & & 5/27/1999 & 34 & & & \\
\hline \multirow[t]{15}{*}{ 1999/2001 } & Grass & 7/18/1999 & 11/1/1999 & & 7/20/1999 & 40 & & & \\
\hline & & & $11 / 1 / 2000$ & & 8/10/1999 & 40 & & & \\
\hline & & & $11 / 1 / 2001$ & & 9/1/1999 & & & 76 & 12 \\
\hline & & & & & 3/21/2000 & & & 297 & 46 \\
\hline & & & & & $4 / 11 / 2000$ & 30 & & & \\
\hline & & & & & $5 / 1 / 2000$ & & & 43 & 7 \\
\hline & & & & & $5 / 1 / 2000$ & 120 & & & \\
\hline & & & & & $7 / 1 / 2000$ & & & 43 & 7 \\
\hline & & & & & 7/1/2000 & 120 & & & \\
\hline & & & & & 4/3/2001 & & & 102 & 15 \\
\hline & & & & & $5 / 1 / 2001$ & & & 102 & 15 \\
\hline & & & & & 5/1/2001 & 70 & & & \\
\hline & & & & & $5 / 31 / 2001$ & & & & \\
\hline & & & & & 7/1/2001 & & & 102 & 15 \\
\hline & & & & & 7/1/2001 & 70 & & & \\
\hline 2002 & Spring barley & 4/1/2002 & 7/16/2002 & 3/29/2002 & 3/29/2002 & & & 120 & 17 \\
\hline & & & & & $4 / 24 / 2002$ & 34 & & & \\
\hline
\end{tabular}




\begin{tabular}{|c|c|c|c|c|c|c|c|c|c|}
\hline & & & & & $7 / 25 / 2002$ & & & 120 & 17 \\
\hline & & & & & 9/1/2002 & & & 120 & 17 \\
\hline \multirow[t]{2}{*}{2003} & Spring barley & 3/30/2003 & 7/9/2003 & $3 / 26 / 2003$ & $3 / 26 / 2003$ & & & 74 & 13 \\
\hline & & & & & $4 / 19 / 2003$ & 27 & & & \\
\hline \multirow[t]{7}{*}{$2003 / 2004$} & Grass & 7/9/2003 & $11 / 1 / 2003$ & & 7/20/2003 & 40 & & & \\
\hline & & & $11 / 1 / 2004$ & & $8 / 1 / 2003$ & & & 74 & 13 \\
\hline & & & & & $3 / 10 / 2004$ & & & 132 & 24 \\
\hline & & & & & 4/1/2004 & 31 & 5 & & \\
\hline & & & & & $5 / 24 / 2004$ & 70 & & & \\
\hline & & & & & $5 / 30 / 2004$ & 21 & & & \\
\hline & & & & & $6 / 24 / 2004$ & 70 & & & \\
\hline \multirow[t]{4}{*}{2005} & Grass & $4 / 2 / 2005$ & $11 / 1 / 2005$ & 3/26/2005 & 3/8/2005 & & & 129 & 24 \\
\hline & & & & & $5 / 14 / 2005$ & 43 & & & \\
\hline & & & & & $6 / 19 / 2005$ & & & 129 & 24 \\
\hline & & & & & $7 / 22 / 2005$ & & & 129 & 24 \\
\hline 2006 & Corn & $5 / 4 / 2006$ & $10 / 16 / 2006$ & $5 / 3 / 2006$ & $5 / 2 / 2006$ & & & 182 & 33 \\
\hline
\end{tabular}


Table 1 Crop rotation and fertilizer application in the monitored tile-drained fields TileL1 and TileL2. The fertilizers have equivalent amounts of mineral nitrogen $(\mathrm{N})$ and phosphorus (P).

\begin{tabular}{llllll}
\hline Year & Crop & \multicolumn{3}{c}{ Mineral fertilizer } & \multicolumn{2}{c}{ Manure } \\
\cline { 3 - 6 } & & $\mathrm{N}\left(\mathrm{kg} \mathrm{N} \mathrm{ha}^{-1}\right)$ & $\mathrm{P}\left(\mathrm{kg} \mathrm{P} \mathrm{ha}^{-1}\right)$ & $\mathrm{N}\left(\mathrm{kg} \mathrm{N} \mathrm{ha}^{-1}\right)$ & $\mathrm{P}\left(\mathrm{kg} \mathrm{Ph}^{-1}\right)$ \\
\hline TileL1 & & & & & \\
$\mathbf{1 9 9 7 / 1 9 9 8}$ & Winter grass & 307.9 & 0 & 182.3 & 58.4 \\
$\mathbf{1 9 9 8} / \mathbf{2 0 0 0}$ & Grass & 157 & 13.1 & 131.3 & 37.7 \\
$\mathbf{2 0 0 0 / 2 0 0 1}$ & Winter wheat & 83.9 & 0 & 125.2 & 35.5 \\
$\mathbf{2 0 0 1 / 2 0 0 2}$ & Winter wheat & 67 & 0 & 160.8 & 48.3 \\
$\mathbf{2 0 0 3}$ & Spring barley & 87 & 0 & 0 & 0 \\
$\mathbf{2 0 0 3 / 2 0 0 4}$ & Grass & 34 & 0 & 127.9 & 34.5 \\
$\mathbf{2 0 0 4 / 2 0 0 5}$ & Winter wheat & 43.19 & 0 & 137.5 & 35.5 \\
$\mathbf{2 0 0 6}$ & Spring barley & 28.14 & 0 & 185 & 46 \\
\hline TileL2 & & & & & \\
$\mathbf{1 9 9 8}$ & Sugar beet & 27 & 0 & 179 & 34 \\
$\mathbf{1 9 9 9}$ & Spring barley & 34 & 0 & 76 & 12 \\
$\mathbf{1 9 9 9 / 2 0 0 1}$ & Grass & 490 & 0 & 765 & 117 \\
$\mathbf{2 0 0 2}$ & Spring barley & 34 & 0 & 360 & 51 \\
$\mathbf{2 0 0 3}$ & Spring barley & 27 & 0 & 74 & 13 \\
$\mathbf{2 0 0 3 / 2 0 0 4}$ & Grass & 0 & 5 & 206 & 37 \\
$\mathbf{2 0 0 5}$ & Grass & 43 & 0 & 387 & 72 \\
$\mathbf{2 0 0 6}$ & Corn & 0 & 0 & 182 & 33 \\
\hline
\end{tabular}

Table 2. Soil organic material (OM), texture, Danish soil texture class (STC), initial soil phosphorus (P) content and the sum of the oxalate extractable iron and aluminium $\left(\mathrm{Fe}_{\mathrm{ox}}+\mathrm{Al}_{\mathrm{ox}}\right)$ in three layers for each soil type in the SWAT2012 model for the Lillebæk and River Odense catchment.

\begin{tabular}{llllllllll}
\hline $\begin{array}{l}\text { SWAT } \\
\text { soil }\end{array}$ & $\begin{array}{l}\text { Soil layers } \\
(\mathrm{mm})\end{array}$ & $\mathrm{OM}(\%)$ & Silt (\%) & $\begin{array}{l}\text { Clay } \\
(\%)\end{array}$ & $\mathrm{STC}$ & $\begin{array}{l}\text { Labile P } \\
\left(\mathrm{mg} \mathrm{kg}^{-1}\right)\end{array}$ & $\begin{array}{l}\text { Mineral } \\
\mathrm{P}^{*}\left(\mathrm{mg} \mathrm{kg}^{-1}\right)\end{array}$ & $\begin{array}{l}\text { Total P } \\
\left(\mathrm{mg} \mathrm{kg}^{-1}\right)\end{array}$ & $\begin{array}{l}\mathrm{Fe}_{\text {ox }}+ \\
\mathrm{Al}_{\text {ox }} \\
\left(\mathrm{mmol}^{-1}\right. \\
\left.\mathrm{kg}^{-1}\right)\end{array}$ \\
\hline \multirow{2}{*}{ DK5037 } & $0-300$ & 1.45 & 15.51 & 7.99 & 3 & 9.6 & 246.5 & 496.8 & 98.5 \\
& $300-700$ & 0.59 & 21.14 & 15.86 & 7 & 6.4 & 176 & 382.8 & 71.6 \\
& $700-1500$ & 0.15 & 20.21 & 18.96 & 7 & 6.9 & 185 & 304.5 & \\
DK5038 & $0-300$ & 1.45 & 15.51 & 7.99 & 3 & 9.6 & 246.5 & 496.8 & 98.5 \\
& $300-700$ & 0.57 & 16.16 & 7.98 & 4 & 4.9 & 121.2 & 280.5 & 73 \\
& $700-1000$ & 0.16 & 13.37 & 8.22 & 4 & 3.6 & 86.7 & 154 & \\
DK5047 & $0-300$ & 1.4 & 20.06 & 8.71 & 4 & 10.5 & 262.2 & 573 & 81.3 \\
& $300-700$ & 0.59 & 21.14 & 15.86 & 7 & 6.4 & 176 & 382.8 & 71.6 \\
& $700-1500$ & 0.15 & 20.21 & 18.96 & 7 & 6.9 & 185 & 304.5 & \\
DK5048 & $0-300$ & 1.4 & 20.06 & 8.71 & 4 & 10.5 & 262.2 & 573 & 81.3 \\
& $300-700$ & 0.57 & 16.16 & 7.98 & 4 & 4.9 & 121.2 & 280.5 & 73 \\
& $700-1000$ & 0.16 & 13.37 & 8.22 & 4 & 3.6 & 86.7 & 154 & \\
DK5067 & $0-300$ & 1.42 & 22.63 & 12.5 & 6 & 10.4 & 272.5 & 573.9 & 75.2 \\
& $300-700$ & 0.59 & 21.14 & 15.86 & 7 & 6.4 & 176 & 382.8 & 71.6 \\
\hline
\end{tabular}

* sum of labile P, active P and stable P in the SWAT model 
Table 3 Parameter ranges and calibrated values for the SWAT2012 model for tile drain and stream flow and DrainP module for dissovled reactive phosphorus leaching (DRP) in TileL1 and TileL2 and Kratholm station on River Odense.

\begin{tabular}{|c|c|c|c|c|c|}
\hline Parameters & Description & Range & TileL1 & TileL2 & Kratholm \\
\hline \multicolumn{6}{|c|}{ SWAT2012 tile flow \&stream flow parameters } \\
\hline CN2 & Curve number for moisture condition II & $15-92$ & 71 & 70 & $20-72 *$ \\
\hline ESCO & Soil evaporation compensation factor & $0.2-0.7$ & 0.25 & 0.23 & 0.64 \\
\hline SOL_AWC & Available water capacity & $0.15-0.34$ & $0.21-0.25^{*}$ & $0.20-0.24 *$ & $0.19-0.30 *$ \\
\hline DDRAIN & Depth of the tile drains (mm) & $800-1200$ & 992 & 958 & 1194 \\
\hline DEP_IMP & $\begin{array}{l}\text { Depth to the impervious layer in the soil } \\
\text { (mm) }\end{array}$ & $1500-4000$ & 3635 & 3726 & 2761 \\
\hline SDRAIN & Distance between two tile drain pipes (mm) & $10000-15000$ & 14286 & 10314 & 10247 \\
\hline DRAIN_CO & Drainage coefficient $\left(\mathrm{mm} \mathrm{day}^{-1}\right)$ & $20-50$ & 26 & 43 & 31 \\
\hline LATKSATF & $\begin{array}{l}\text { Multiplication factor to determine lateral } \mathrm{K}_{\text {sat }} \\
\text { from SWAT } \mathrm{K}_{\text {sat }}\end{array}$ & $1-4$ & 3.3 & 3.0 & 2.4 \\
\hline ALPHA_BF & Base flow factor & $0.6-1$ & & & 0.83 \\
\hline GW_DELAY & Groundwater delay time (day) & 20-100 & & & 86 \\
\hline RCHRG_DP & $\begin{array}{l}\text { Ratio of groundwater entering the deep } \\
\text { aquifer }\end{array}$ & $0.02-0.3$ & & & 0.24 \\
\hline CH_K2 & $\begin{array}{l}\text { Effective hydraulic conductivity in main } \\
\text { channel alluvium }(\mathrm{mm} / \mathrm{hr})\end{array}$ & $60-120$ & & & 65.6 \\
\hline \multicolumn{6}{|c|}{ DrainP DRP leaching parameters } \\
\hline $\boldsymbol{k}_{\mathbf{L}}$ & $\begin{array}{l}\text { Langmuir adsorption constant }(1 / \mathrm{mg}) \text { for } 0-30 \mathrm{~cm} \\
\text { soil }\end{array}$ & $0.50-2.40$ & 1.11 & 0.61 & 0.53 \\
\hline $\boldsymbol{\beta}_{m}$ & Maximum adsorption fraction for $0-30 \mathrm{~cm}$ soil & $0.06-0.23$ & 0.10 & 0.11 & 0.08 \\
\hline
\end{tabular}

* Range of values for different soil types and soil layers

Table 4 Sensitivity analysis of the Langmuir adsorption constant $\left(k_{L}\right)$ and maximum adsorption fraction $\left(\beta_{m}\right)$ on dissolved reactive phosphorus (DRP) yields in tile-drained fields TileL1 and TileL2 and Kratholm station on River Odense. $t$-Stat is the result from a $t$-test, where larger absolute values indicate higher sensitivity. $P$ Value determines the significance of the sensitivity.

\begin{tabular}{lllll}
\hline & \multicolumn{2}{c}{$k_{L}$} & \multicolumn{2}{c}{$\beta_{m}$} \\
\hline & t-Stat & $P$-Value & t-Stat & $P$-Value \\
TileL1 & -1.8 & 0.07 & 3.6 & 0.0003 \\
TileL2 & -10.1 & 0 & -38.6 & 0 \\
Kratholm & -18.4 & 0 & -52.8 & 0 \\
\hline
\end{tabular}

Table 5 Contributions (\%) of different sources to the average annual stream flow simulated by the SWAT2012 model and average annual dissolved reactive phosphorus (DRP) yields simulated by the extended SWAT2012 with DrainP module from 1998 to 2006 at Kratholm station on River Odense.

\begin{tabular}{llll}
\hline Sources & Stream flow & \multicolumn{2}{l}{ DRP transport } \\
\hline & SWAT2012 & SWAT2012 & DrainP \\
Surface runoff & 7 & 25 & 20 \\
Groundwater & 49 & 55 & 25 \\
Tile drains & 38 & - & 46 \\
Lateral flow & 4 & - & - \\
Point source & 2 & 20 & 9 \\
\hline Sum & 100 & 100 & 100 \\
\hline
\end{tabular}


Figure 1 Illustration of how soil layers between the shallow water table (swt) and the tile drain depth (DDRAIN) contribute to the tile drain flow $\left(\boldsymbol{f} \boldsymbol{r}_{\text {tile, }, \boldsymbol{l}}\right)$.

Figure 2 (a) Location of the Lillebæk and River Odense catchments in Denmark; (b) elevation map of the Lillebæk catchment; (c) land use of the Lillebæk catchment; (d) soil map of the Lillebæk catchment.

Figure 3 (a) and (b) Monthly tile drain flow yield observed in the tile-drained fields TileL1 and TileL2 in the Lillebæk catchment (Obs) and simulated by the SWAT model version 2012 (SWAT2012); (c) monthly stream discharge observed at the Kratholm station on River Odense (Kratholm) and simulated by the SWAT2012. NSE stands for Nash-Sutcliffe Efficiency and PBIAS for percent bias.

Figure 4 (a) and (b) Monthly dissolved reactive phosphorous (DRP) yields observed in the tile-drained fields TileL1 and TileL2 in the Lillebæk catchment (Obs), simulated by SWAT2012 with the DrainP module (DrainP), and the 95\% prediction uncertainty band (95PPU) of DrainP; (c) monthly DRP yields observed in River Odense at the Kratholm station (Obs), the SWAT2012, DrainP and 95PPU of DrainP. NSE stands for Nash-Sutcliffe Efficiency and PBIAS for percent bias.

Figure 5 (a) Dissolved reactive phosphorous (DRP) concentrations observed in the tile-drained fields TileL1 and TileL2 in the Lillebæk catchment against simulated by SWAT2012 extended with the DrainP module (DrainP) during the study period; (b) DRP concentrations observed in River Odense at the Kratholm station against simulations from the DrainP model.

Figure 6 (a) Total phosphorus (TP) increase at 0-30 cm depth in the tile-drained fields TileL1 and TileL2 in the Lillebæk catchment. The TP increase is calculated as the annual mean soil TP content minus the initial soil TP in 1989; (b) average annual soil TP increase at 0-30 cm depth of all soil types in agricultural areas in the River Odense catchment upstream station Kratholm. Error bars indicate standard errors of the mean. Red dots in (a) and (b) indicate the means of the measured TP increase from 1986 to 1998 for the soil texture class (STC) at 0-25 cm depth from the nationwide grid sampling programme. Initial soil TP contents are given in Table 2.

Figure 7 Average annual phosphorus (P) budget from 1998 to 2006 in tile-drained fields TileL1 (a), TileL2 (b) and in the River Odense catchment upstream Kratholm station (c). P yield comprises harvest yield 
includes P export with harvested crops and in addition a small hardly visible contribution of P lost through soluble and particulate P in surface runoff, tile drain flow, lateral flow and leaching out of the soil profile. 